\title{
FAKTOR PREDISPOSISI, PEMUNGKIN DAN PENDORONG DALAM PENINGKATAN PARTISIPASI LAKI-LAKI PADA KEGIATAN POSYANDU DI KABUPATEN LEBAK
}

\section{PREDISPOSING, ENABLING, AND REINFORCING FACTORS IN IMPROVING MALE PARTICIPATION IN POSYANDU ACTIVITIES IN LEBAK REGENCY}

\author{
Rery Kurniawati Danu Iswanto, Nintinjri Husnida, Hani Sutianingsih \\ Poltekkes Kemenkes Banten \\ Korespondensi: bundamanua@yahoo.com
}

\begin{abstract}
A model for promotion, education, and changes in health behavior will be effective if supported by active participation from the role of men. However, posyandu as the leading health service for mothers and children in general in the community is only managed by women's resources, its starting from health workers, cadres, and targets. Based on this, a posyandu service model which involves men in each aspect was examined, both health workers, cadres, and targets. One theory of behavior change that is relevant in describing a series of efforts to change health behavior from planning to resolving public health problems is the theory of behavior change by Lawrence Green (1979). With this approach model, it is hoped that the posyandu services will be strengthened and will have an impact on improving public health.

The design of this study is qualitative analysis through several stages of research. The first stage will be a preliminary study on several posyandu where the research subjects live to explore the social characteristics of the community. Then conduct group focus discussions to explore predisposing factors, enabling factors, and reinforcing factors in relation to the participation of men in the posyandu. The third stage is compiled a model or scheme of the L.Green theory approach in increasing male participation based on research data. The data is processed and presented qualitatively.

The results showed predisposing factors as posyandu cadres, the main work to provide for family, free time, and motivation. As a target for posyandu, education level and type of work. The enabling factor was found as posyandu cadres: facilities / infrastructure and compensation. As a target for posyandu: posyandu schedule. And reinforcing factors as posyandu cadres, support for puskesmas/health services and support from community leaders. As a target for posyandu, family support and work support.
\end{abstract}

Keywords: Predisposing factors, enabling factors, reinforcing factors, male participation, Posyandu

\begin{abstract}
ABSTRAK
Suatu model promosi, edukasi, dan perubahan perilaku kesehatan akan efektif jika didukung oleh partisipasi aktif dari peran laki-laki. Akan tetapi, posyandu sebagai layanan kesehatan terdepan bagi ibu dan anak pada umumnya di masyarakat hanya
\end{abstract}


dikelola oleh sumber daya perempuan mulai dari tenaga kesehatan, kader, dan sasarann. Berdasarkan hal tersebut diteliti suatu model layanan posyandu yang melibatkan lakilaki dalam setiap aspeknya baik tenaga kesehatan, kader, maupun sasarannya. Salah satu teori perubahan perilaku yang relevan dalam menggambarkan rangkaian upaya perubahan perilaku kesehatan mulai dari perencanaan sampai dengan menyelesaikan masalah kesehatan masyarakat adalah teori perubahan perilaku oleh L. Green (1979). Dengan model pendekatan ini diharapkan akan menguatkan layanan posyandu dan berdampak pada peningkatan derajat kesehatan masyarakat.

Desain penelitian ini adalah analisis kualitatif melalui beberapa tahap penelitian. Tahap pertama akan dilakukan studi pendahuluan pada beberapa posyandu dimana subyek penelitian tinggal untuk menggali karakteristik sosial masyarakatnya. Selanjutnya melakukan diskusi fokus grup untuk menggali faktor predisposisi, faktor pemungkin, dan faktor pendorong dalam kaitannya dengan partisipasi laki-laki di posyandu. Tahap ketiga disusun suatu model atau skema pendekatan teori Green (1979) dalam peningkatan partisipasi laki-laki berdasarkan dari data penelitian. Adapun data diolah dan disajikan secara kualitatif.

Hasil penelitian menunjukkan faktor predisposisi responden sebagai kader posyandu, pekerjaan pokok responden adalah untuk menafkahi keluarga, sebagai pengisi waktu luang, dan motivasi. Sebagai sasaran posyandu, tingkat pendidikan dan jenis pekerjaan. Faktor enabling ditemukan sebagai kader posyandu: sarana/prasarana dan kompensasi. Sebagai sasaran posyandu: jadwal posyandu. Dan faktor pendorong sebagai kader posyandu, dukungan puskesmas/dinas kesehatan dan dukungan tokoh masyarakat. Sebagai sasaran posyandu, dukungan keluarga dan dukungan pekerjaan.

\section{Kata Kunci : Faktor Predisposisi, Faktor Pemungkin, Faktor Pendorong, Partisipasi Laki-laki, Posyandu}

\section{PENDAHULUAN}

Posyandu sebagai layanan kesehatan ibu dan anak yang terdepan merupakan upaya kesehatan yang bersifat partisipatif yaitu dari, oleh dan untuk masyarakat. Hampir setiap desa di Indonesia memiliki posyandu. Pada dasarnya posyandu adalah milik masyarakat sehingga pengelolaannya pun dilakukan oleh masyarakat.

Yang menjadi perhatian adalah seolah-olah posyandu merupakan partisipasi masyarakat yang hanya melibatkan perempuan mulai dari pengelolaan, kader, sasaran. Bahkan tenaga kesehatan yang terlibat di posyandu pada umumnya hanya diperankan oleh perempuan. Kalaupun ada laki-laki yang terlibat tidak secara langsung masuk dalam struktur posyandu,akan tetapi hanya sebatas membantu kegiatan fisik dalam menyiapkan sarana posyandu. Padahal di negara dengan budaya masyarakatnya sebagian besar adalah patriarki, keberadaan, peran atau partisipasi laki- 
laki sangat diperlukan. Tidak hanya sebatas peran fisik akan tetapi juga partisipasi dalam pengelolaan posyandu, penyuluhan kesehatan, dll. Kader posyandu laki-laki akan sangat membantu dalam mensosialisasikan kegiatan-kegiatan posyandu dan informasi-informasi kesehatan kepada masyarakat laki-laki (paman, sepupu, teman, dll). Sasaran posyandu selama ini hanya untuk ibu dan anak. Intervensi di posyandu menjadi tidak efektif ketika setiap layanan ataupun informasi yang didapat oleh ibu dan anak di posyandu pada akhirnya tidak diterapkan karena suami tidak berperan memberikan dukungan. Oleh karena itu, penting bagi laki-laki untuk menjadi sasaran posyandu, agar layanan kesehatan yang di terima keluarga lebih komprehensif.

Suatu model promosi, edukasi, dan perubahan perilaku kesehatan akan efektif jika didukung oleh partisipasi aktif dari peran laki-laki. Akan tetapi, posyandu sebagai layanan kesehatan terdepan bagi ibu dan anak pada umumnya di masyarakat hanya dikelola oleh sumber daya perempuan mulai dari tenaga kesehatannya, kader, dan bahkan sasarannya. Berdasarkan hal tersebut peneliti mendesain suatu model pendekatan layanan posyandu yang melibatkan laki-laki dalam setiap aspeknya baik tenaga kesehatan, kader, maupun sasarannya. Salah satu teori perubahan perilaku yang relevan dalam menggambarkan rangkaian upaya perubahan perilaku kesehatan mulai dari perencanaan sampai dengan menyelesaikan masalah kesehatan masyarakat adalah teori precede-proceed yang dikenalkan oleh Lawrence Green (1979). Dengan model pendekatan ini diharapkan akan menguatkan layanan posyandu dan berdampak pada peningkatan derajat kesehatan masyarakat.

\section{METODE}

Desain penelitian ini adalah analisis data kualitatif deskriptif dengan melakukan beberapa tahap penelitian. Tahap pertama akan dilakukan studi pendahuluan pada beberapa posyandu sebagai subyek penelitian untuk menggali karakteristik, faktor predisposing, factor enabling, dan factor reinforcing dalam partisipasi laki-laki yang dapat diterapkan di posyandu. Tahap kedua akan disusun suatu model pendekatan precede-proceed dalam peningkatan partisipasi laki-laki berdasarkan data-data dari studi 
pendahuluan. Adapun data diolah dan disajikan secara kualitatif.

Tujuan penelitian kualitatif adalah mengembangkan konsep-konsep yang membantu pemahaman lebih mendalam atas fenomena sosial dan perilaku dalam setting alamiah dalam arti peneliti tidak berusaha untuk memanipulasi setting penelitian melainkan melakukan studi terhadap suatu fenomena dimana fenomena tersebut ada.

$$
\text { Populasi penelitian adalah }
$$
posyandu di wilayah I Kabupaten Lebak terdiri dari 4 puskesmas yaitu Puskesmas Mandala, Puskesmas Rangkasbitung, Puskesmas Warunggunung, dan Puskesmas Baros. Sampel diambil berdasarkan purposive sampling dengan tujuan mendapatkan responden yang kaya akan informasi data penelitian (rich informan). Jumlah sampel ditentukan dengan mempertimbangkan ketercapaian data secara kualitatif. Dalam penelitian ini sampel yang diambil sebanyak 11 orang. Terdiri dari bidan sebanyak 8 orang dan kader sebanyak 3 orang. Sedangkan triangulasi dilakukan pada pengelola di puskesmas sebanyak 2 orang.

Data yang digunakan adalah data primer. Alat yang digunakan untuk mengumpulkan data adalah kuesioner dan lembar observasi yang disusun sendiri oleh peneliti. Pengumpulan data dengan kuesioner dilakukan dengan wawancara mendalam tentang topik penelitian. Cara pengambilan data penelitian dilakukan berulang-ulang secara seksama sampai mendapatkan kecukupan data. Data hasil wawancara dan observasi tersebut selanjutnya dikategorikan secara kualitatif. Selanjutnya data diolah secara kualitatif menggunakan metode analisis konten. Tahap pertama data dikodifikasi dalammatriks data berdasarkan kategori tertentu. Kemudian transkrip data di analisis kontennya, sehingga didapatkan kesimpulan induktif yang menggambarkan pola-pola tertentu sebagai kesimpulan penelitian.

\section{HASIL DAN PEMBAHASAN}

Hasil penelitian ini didapatkan suatu rancangan model partisipasi lakilaki dalam kegiatan posyandu. Dengan pertimbangan ketiga faktor yaitu predisposing, enabling, dan reinforcing didapatkan suatu model pelaksanaan posyandu dengan lebih banyak keterlibatan laki-laki sebagai berikut: 


\section{Sebagai kader posyandu}

Tahap persiapan posyandu

Melakukan persiapan-persiapan:

- Mengumumkan jadwal kegiatan

- Menyiapkan sarana prasarana

- Melobi pihak-pihak terkait

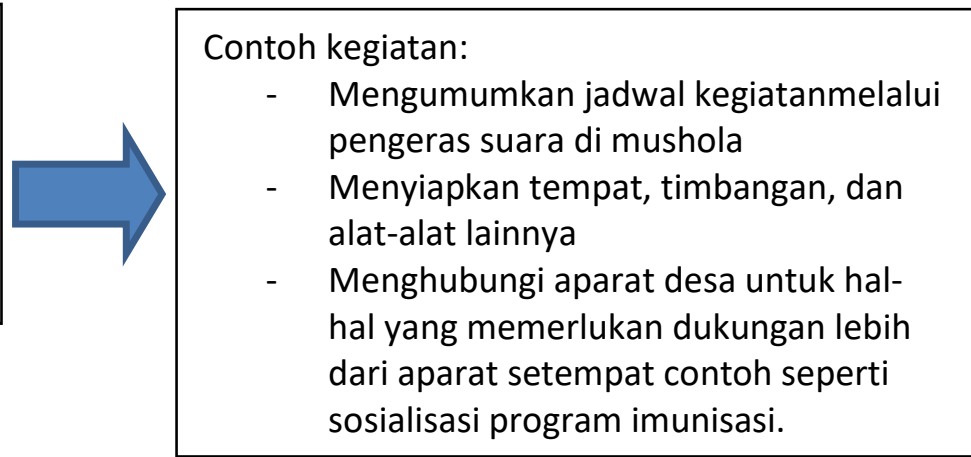

Tahap pelaksanaan posyandu

Melakukan kegiatan posyandu:

- Melakukan kegiatan dimeja 1, 2, 3, dan 5

- Mengantar/jemput bola sasaran posyandu

- Melakukan sweaping sasaran yang belum terjangkau

\section{Contoh kegiatan:}

- Mencatat dan mendata sasaran

- Melakukan penimbangan

- Memberikan penyuluhan kesehatan

- Mengantar/jemput bola sasaran yang terkendala geografis maupun transportasi

- Menjangkau sasaran yang sulit/belum mendapatkan layanan diposyandu

\section{Sebagai sasaran posyandu}

Tahap persiapan posyandu

Melakukan persiapan-persiapan:

- Mengingat jadwal posyandu

- Menyiapkan transportasi
Contoh kegiatan:

- Mengingatkan jadwal posyandu pada istri/anaknya

- Menyiapkan kendaraan atau uang jika diperlukan

Tahap pelaksanaan posyandu

Melakukan kegiatan posyandu:

- Mengantar dan menemani istri/anak selama kegiatan posyandu

- Mengikuti penyuluhan kesehatan di posyandu

- Membantu mengambil keputusan terkait asuhan pada istri/anak
Contoh kegiatan:

- Melakukan penimbangan anaknya

- Mendengarkan penyuluhan kesehatan

- Terlibat dalam menentukan alat kontrasepsi yang dipakai

- Menenangkan anak yang rewel 
Karakteristik Partisipasi Laki-Laki Dalam Pelaksanaan Posyandu

Pernyataan yang dapat diambil mengenai karakteristik partisipasi lakilaki dalam pelaksanaan posyandu berdasarkan hasil penelitian ini adalah:

1. Sebagai kader posyandu:

- Laki-laki mempunyai kemampuan yang baik dalam melakukan lobi dan memberikan pengaruh pada masyarakat. Hal ini sangat dibutuhkan ketika ada kasus-kasus tertentu yang memerlukan koordinasi dengan aparat desa dan lintas sektor lainnya.

- Kader laki-laki mempunyai mobilitas yang lebih baik untuk menjangkau daerah geografis yang sulit maupun dalam melakukan jemput bola sasaransasaran posyandu yang sulit dijangkau.

- Laki-laki sebagai pencari nafkah dalam keluarga pada umumnya dan menggunakan sebagian besar waktunya untuk bekerja sehingga sulit banyak terlibat di kegiatan posyandu.

- Beberapa kader laki-laki yang pernah terlibat diposyandu hanya menjadikan keterlibatannya sebagai kader posyandu sebagai kegiatan sampingan sehingga tidak bertahan lama dan berhenti menjadi kader dengan alasan mendapat pekerjaan baru.

Hal ini didukung oleh pernyataan salah satu subyek yang menyatakan bahwa "...pernah ada kader laki-laki, enak sih bu karena ada yang bisa menjangkau sasaran yang jauh, bisa antar jemput, punya power atau pengaruh untuk membujuk masyarakat, tapi sekarang sudah diangkat jadi hansip jadi tidak jadi kader lagi...”.

Hal tersebut juga sejalan dengan pernyataan Nurul (2014) bahwa kader Posyandu dan Pos Pembinaan Terpadu (Posbindu) identik dengan kaum perempuan. Padahal keterlibatan kaum laki-laki dibutuhkan misal untuk mengangkat timbangan, meja, kursi, dan lain sebagainya.

2. Sebagai sasaran posyandu:

- Tidak ada laki-laki yang datang ke posyandu terlibat sebagai sasaran posyandu.

- Sebagai suami, laki-laki pada umumnya mempunyai kewenangan lebih dalam pengambilan keputusan apapun terkait asuhan/kegiatan yang dilakukan istri/anaknya di posyandu. 
- Suami cenderung lebih banyak waktu untuk bekerja dan tidak terlibat dalam kegiatan posyandu.

- Ada trend di kalangan suamisuami dilingkungan perumahan/komplek, ketika jadwal posyandu bertepatan dengan hari libur mereka lebih banyak ikut terlibat dalam kegiatan posyandu.

Pernyataan tersebut sesuai dengan keterangan subyek yang menyatakan bahwa “......tidak ada sasaran atau peserta KB pria datang ke posyandu karena mereka mah di data oleh petugas KB....peserta penyuluhan juga gak ada bapak-bapak, tapi ada bapakbapak yang datang ke posyandu kalau hari sabtu/minggu nganter istri dan anaknya, biasanya yang begitu malah bapak-bapak yang terpelajar bu....."

Hal tersebut tidak sejalan dengan yang tertuang dalam referensi Depkes (2006) yang menyatakan bahwa sasaran posyandu adalah seluruh masyarakat terutama adalah bayi, anak balita, ibu hamil, ibu melahirkan, ibu nifas, ibu menyusui dan pasangan usia subur, lansia. Seluruh masyarakat dalam hal ini adalah tentusaja termasuk para suami.

Faktor Predisposing Partisipasi LakiLaki Dalam Pelaksanaan Posyandu
Beberapa faktor predisposisi dalam partisipasi laki-laki di posyandu adalah:

1. Sebagai kader posyandu:

- Pekerjaan pokok untuk menafkahi keluarga. Beberapa kader laki-laki yang pernah atau sedang terlibat di posyandu menyatakan bahwa kegiatan yang dilakukan di posyandu bukanlah pekerjaan utama untuk mencari nafkah. Karena posyandu memang merupakan kegiatan yang bersifat partisipasi masyarakat yang tidak memberikan pendapatan bagi orang-orang yang terlibat dalam pelaksanaan kegiatannya. Oleh karena itu, jika kader laki-laki tersebut mendapatkan pekerjaan yang harus mengurangi atau meninggalkan kegiatannya di posyandu maka kegiatan tersebut akan ditinggalkan.

- Waktu luang. Meski pelaksanaan posyandu hanya satu bulan sekali, akan tetapi banyak kegiatankegiatan seperti pendataan, penyuluhan, dan lain-lain yang dilakukan diluar jadwal posyandu. Oleh karena itu, kader harus dapat meluangkan waktu bekerja atau aktifitas lainnya untuk 
pelaksanaan kegiata-kegiatan di posyandu tersebut. Hal tersebut yang menjadi hambatan bagi kader laki-laki yang mempunyai pekerjaan pokok lainnya.

- Motivasi. Memerlukan motivasi yang besar baik sebagai kader laki-laki maupun perempuan untuk terlibat dalam kegiatan posyandu. Karena posyandu adalah kegiatan yang bersifat partisipatif dan dilakukan swadaya oleh masyarakat, sehingga yang terlibat sebagai kader posyandu pada umumnya adalah orangorang yang mempunyai motivasi yang tinggi untuk berpartisipasi.

\section{Sebagai sasaran posyandu:}

- Tingkat pendidikan. Suami-suami dengan tingkat pendidikan yang tinggi cenderung lebih banyak hadir di posyandu baik sekedar mengantar maupun menemani istri/anaknya selama pelaksanaan posyandu. Pendidikan yang tinggi sepertinya membangun persepsi individu/suami yang baik bahwa keterlibatan suami dalam kegiatan posyandu adalah penting.

- Jenis pekerjaan. Suami dengan jenis pekerjaan yang mempunyai jadwal libur teratur, lebih banyak terlibat dan menggunakan waktu liburnya untuk mengikuti kegiatan di posyandu.

\section{Faktor Enabling Partisipasi Laki-Laki Dalam Pelaksanaan Posyandu} Beberapa faktor enabling/pemungkin dalam partisipasi laki-laki di posyandu adalah:

1. Sebagai kader posyandu:

Sarana/prasarana. Dengan tersedianya sarana transportasi misalnya kendaraan roda dua akan membantu kader dalam pelaksanaan kegiatan di posyandu.

- Kompensasi. Kompensasi berupa tunjangan ataupun bentuk fasilitas lain seperti keanggotaan jaminan kesehatan gratis akan membantu kebutuhan kader.

2. Sebagai sasaran posyandu:

- Jadwal posyandu. Jadwal posyandu yang dapat disesuaikan dengan waktu luang/libur para suami, memungkinkan keterlibatan yang lebih banyak bagi para suami untuk hadir di posyandu.

Faktor Reinforcing Partisipasi LakiLaki Dalam Pelaksanaan Posyandu

Beberapa

faktor reinforcing/pendukung dalam partisipasi laki-laki di posyandu adalah: 1. Sebagai kader posyandu: 
- Dukungan puskesmas/dinas kesehatan. Puskesmas/dinas kesehatan yang memberikan kesempatan lebih banyak untukmerekrut kader laki-laki dan memberikan fasilitas untuk pelaksanaan kegiatan posyandu.

Dukungan tokoh masyarakat. Aparat desa bekerjasama dengan kader dan memberikan dukungan baik berupa materi maupun non materi.

2. Sebagai sasaran posyandu:

- Dukungan keluarga. Keluarga mendorong para suami untuk lebih banyak terlibat dalam kegiatan posyandu.

- Dukungan pekerjaan. Sedapat mungkin pekerjaan diatur agar suami tetap dapat terlibat dalam kegiatan diposyandu di sela-sela jadwal pekerjaannya.

Hal tersebut sejalan dengan program keluarga sehat yang disosialisasikan oleh Kementerian Kesehatan (2016) bahwa perlu dilakukan pemberdayaan keluarga, yakni menggugah partisipasi segenap keluarga (sebagai kelompok masyarakat terkecil) untuk berperilaku hidup sehat.

Sejalan dengan hasil penelitian Maryati (2017) yang menyatakan bahwa partisipasi ayah dalam mengantarkan balita ke posyandu meningkat seiring kesadaran akan pentingnya masa generasi emas pada pertumbuhan balita.

\section{SIMPULAN}

Penelitian ini dapat di simpulkan bahwa:

1. Karakteristik Partisipasi Laki-Laki Dalam Pelaksanaan Posyandu

Sebagai kader posyandu laki-laki mempunyai kemampuan yang baik dalam melakukan lobi, mobilitas yang lebih baik, sebagai pencari nafkah dalam keluarga pada umumnya dan menggunakan sebagian besar waktunya untuk bekerja dan keterlibatannya sebagai kader posyandu hanyasebagai kegiatan sampingan.

Sebagai sasaran posyandu, tidak ada laki-laki yang datang ke posyandu terlibat sebagai sasaran posyandu. Akan tetapi sebagai suami, laki-laki pada umumnya mempunyai kewenangan lebih dalam pengambilan keputusan, cenderung lebih banyak waktu untuk bekerja dan tidak terlibat dalam kegiatan posyandu. Dan ada trend di kalangan suami-suami dilingkungan perumahan/komplek, lebih banyak ikut terlibat dalam kegiatan posyandu. 
2. Faktor Predisposing Partisipasi LakiLaki Dalam Pelaksanaan Posyandu

Sebagai kader posyandu: pekerjaan pokok untuk menafkahi keluarga, waktu luang, dan motivasi.

Sebagai sasaran posyandu: tingkat pendidikan dan jenis pekerjaan.

3. Faktor Enabling Partisipasi LakiLaki Dalam Pelaksanaan Posyandu Sebagai kader posyandu: sarana/prasarana dan kompensasi.

Sebagai sasaran posyandu: jadwal posyandu.

4. Faktor Reinforcing Partisipasi LakiLaki Dalam Pelaksanaan Posyandu Sebagai kader posyandu: dukungan puskesmas/dinas kesehatan dan dukungan tokoh masyarakat.

Sebagai sasaran posyandu: dukungan keluarga dan dukungan pekerjaan

\section{DAFTAR PUSTAKA}

Aminuddin. Zulkifli, Andi. Djafar, Nurhaedar. Peningkatan Peran Posyandu Partisipatif melalui Pendampingan dan Pelatihan Upaya Pemantauan Pertumbuhan dan Masalah Gizi Balita di Bone, Sulawesi Selatan. Jurnal Kesehatan Masyarakat Nasional Vol. 5, No. 5, April 2011.
Emillia Ova. Promosi Kesehatan Dalam Lingkup Kesehatan Reproduksi, Pustaka Cendekia, Yogyakarta. 2008.

Green L. Health Promotion Planning An Educational and Environmental Approach. Mayfield Publishing Company. USA. 2000.

Kementerian Kesehatan RI. Pedoman Umum Program Indonesia Sehat dengan Pendekatan Keluarga. Jakarta: Kementerian Kesehatan RI., 2016.

Maryati, Heni. Prihatini, MS. Dukungan Kader Posyandu Terhadap PartisipasiAyah Peduli Balita Dalam Upaya Pelayanan Kesehatan. Prosiding Seminar Nasional Hasil Penelitian dan Pengabdian Masyarakat Seri Ke-1 Tahun 2017.

Notoatmodjo S. Promosi Kesehatan dan Ilmu Perilaku. PT. Rineka Cipta. Jakarta. 2007.

Nurul H, perlunya laki-laki jadi kader posyandu dan posbindu. https://www.depok.go.id/05/12/2014/03kesehatan-kota-depok. Diakses 20 November 2018.

Pusat Komunikasi Publik Sekretariat Jenderal Kementerian Kesehatan RI, website: www.depkes.go.id, diakses 01 Oktober 2013

Rovea Ernazelle G. Austria, Carl Abelardo T. Antonio; Male Involvement In Maternal Health, Philiphine Journal Of Health Research And Development, Vol 21 no 2, Austria. 2017.

Suharsaputra, Uhar. Metode Penelitian Kuantitatif, Kualitatif, dan Tindakan. Refika Aditama. 2012. An Integrative Framework for Community Partnering to Translate Theory into Effective Health Promotion Strategy, Volume: 18 issue: 2, page(s): 168-176 Issue published: November 1, 2003 